\title{
Eutypa Dieback of Grapevine and Apricot
}

\author{
Gary P. Munkvold, Department of Plant Pathology, Iowa State University, Ames, IA 50010
}

Corresponding author: Gary P. Munkvold. munkvold@iastate.edu

Munkvold, G. P. 2001. Eutypa dieback of grapevine and apricot. Online. Plant Health Progress doi:10.1094/PHP-20010219-01-DG.

\section{Disease: Eutypa dieback}

Primary Economic Host: Vitis L. spp. (grapevine), Prunus armeniaca L. (apricot)

Pathogen: Eutypa lata (Pers:Fr.) Tul. \& C. Tul. (=Eutypa armeniacaeHansf. \& Carter). Anamorph: Libertella blepharis A.L. Sm. (=Cytosporina Sacc. sp.)

\section{Taxonomy}

The pathogen on apricot was originally described as E. armeniacae (1). However, in many recent publications this species has been considered conspecific with $E$. lata $(17,18)$, a species with a very broad host range. In contrast, some researchers maintain that only the strains pathogenic to cultivated fruit trees and grapevine belong to E. armeniacae and that isolates from other woody dicots are E. lata $(9,10)$. Molecular data support the existence of two distinct species, both occurring on cankered grapevines (8). For descriptions of the genus Eutypa, see Glawe and Rodgers (10) and Rappaz (17).

\section{Symptoms and Signs}

Grapevine. Symptoms of Eutypa dieback do not usually appear until vines are at least six years old. Shoot symptoms are most evident during the spring, when healthy shoots are $20-40 \mathrm{~cm}$ long. Shoots arising from infected wood are stunted with small, chlorotic, distorted leaves (2)(Fig. 1, 2a). The leaves become necrotic and tattered as the season progresses. Fruit fails to develop or develops very poorly (Fig. 2b). No other pathogens are known to cause these shoot symptoms. The symptoms can resemble herbicide injury, but Eutypa dieback does not cause shoot bunching, vein clearing or banding. Eutypa dieback shoot symptoms are always accompanied by a canker, which often appears V-shaped in a crosssection of the perennial wood (Fig. 3). Similar cankers can be caused by other fungi, and canker shape alone is not diagnostic for Eutypa dieback. Cankers have a definite margin between the live and dead wood. The cankers can be traced back to old pruning wounds by scraping the bark from the trunk or cordon. Spurs bearing stunted shoots usually die the following year. Over a period of years, cankers progress toward the trunk, killing the distal portions of the vine (Fig. 4). Cankered wood becomes distorted and twisted after a number of years. Eventually, the entire vine is killed (Fig. 5). Spurs or cordons may be killed without the development of shoot symptoms. In this case, diagnosis depends on the presence of a canker and isolation of the pathogen. In areas of high rainfall or under sprinkler irrigation, vines older than ten years may develop perithecia on the dead xylem tissue of cankers. Perithecia are embedded in stromata of fungal and host tissue. The stromata are black, usually cracked, and sometimes punctate. Perithecial cavities can be seen by scraping the surface of the stromata with a sharp knife or scalpel (Fig. 6). Asexual spores, which are not believed to be infectious on any host, develop in pycnidia on the inner bark or intermingled with perithecia. The distribution of diseased vines is usually random, but large patches of affected vines can develop in old vineyards where perithecia are present.

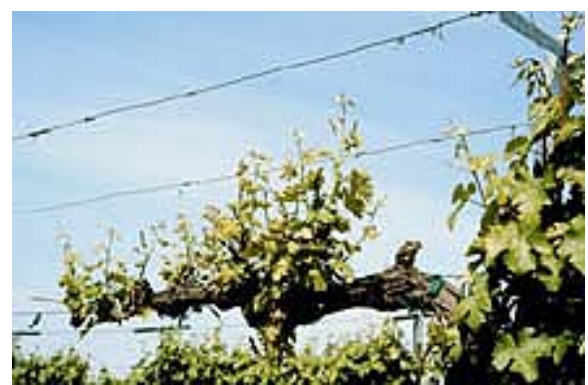

Fig. 1a. Cordon-pruned vine severely affected by Eutypa dieback. One spur is dead, and the others have stunted shoots with chlorotic leaves. Healthy shoots on the other cordon can be seen at right.

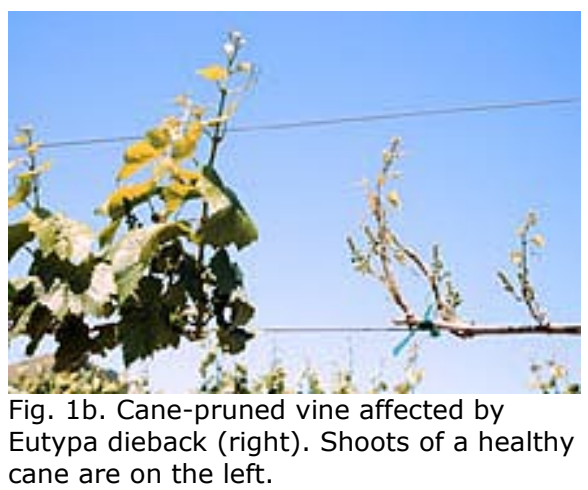

dieback (right). Shoots of a healthy cane are on the left. 


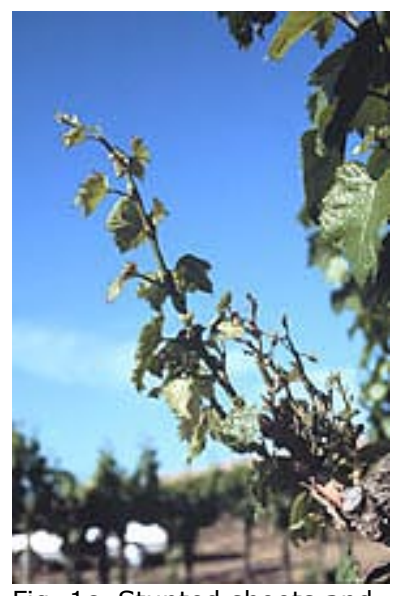

Fig. 1c. Stunted shoots and leaves on a head-pruned vine. Leaves of a healthy shoot can be seen at the upper right.

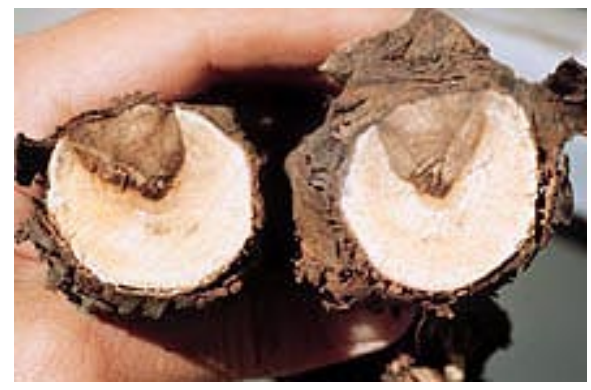

Fig. 3. V-shaped canker caused by Eutypa lata in the xylem of a grapevine cordon.

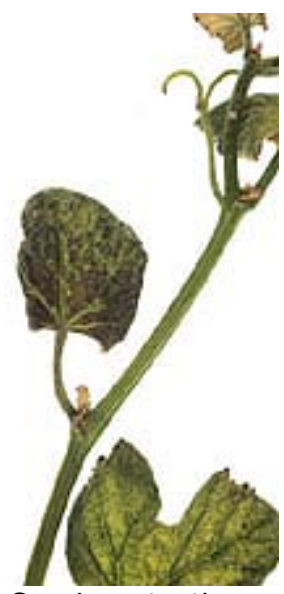

Fig. 2a. Cupping, stunting, chlorosis, and necrosis of leaves on a shoot affected by Eutypa dieback.
Fig. 2b. Cluster development on an affected shoot (right) and a healthy shoot (left) from the same vine.

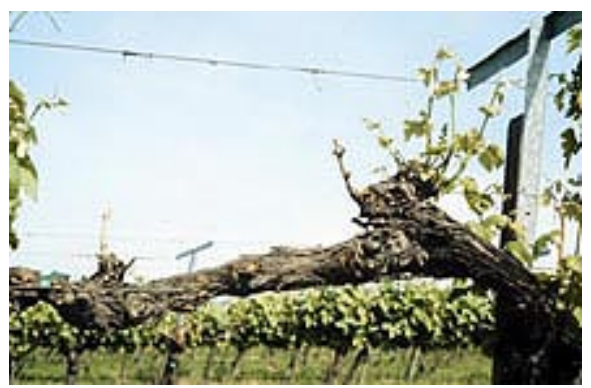

Fig. 4. The distal portion of this cordon was killed by Eutypa lata.

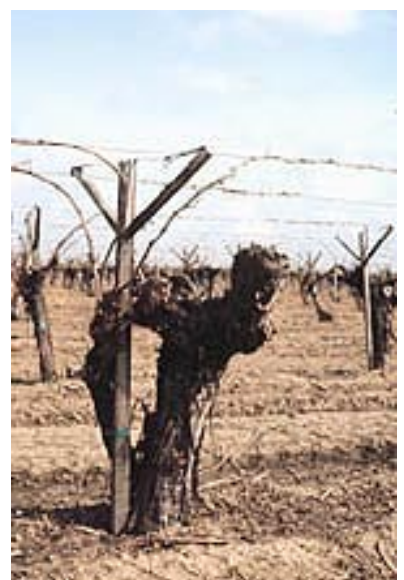

Fig. 5. The main trunk (right) of this vine died due to Eutypa dieback, and a new shoot (left) was trained as a replacement vine. 


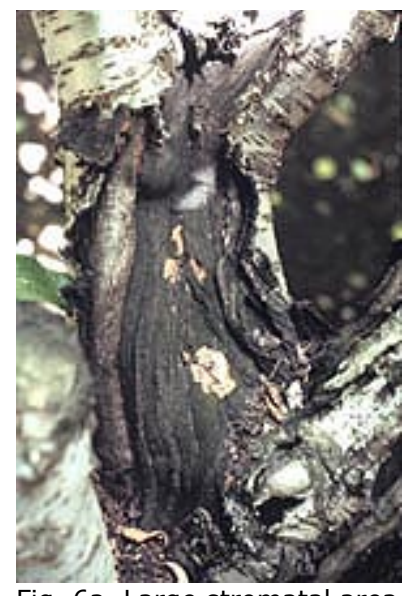

Fig. 6a. Large stromatal area on the trunk of a Bing cherry tree.

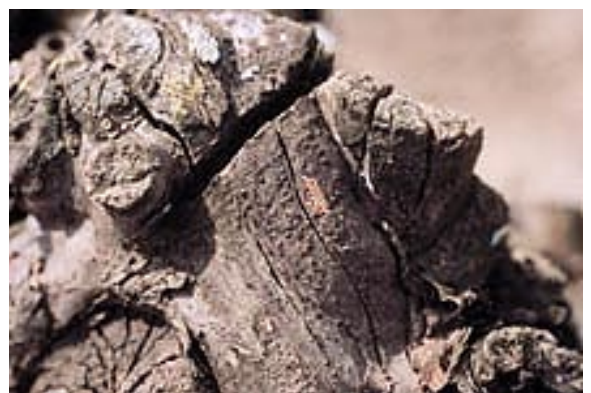

Fig. 6b. Stroma of $E$. lata on a grapevine, with perithecial cavities exposed by scraping the surface of the stroma.

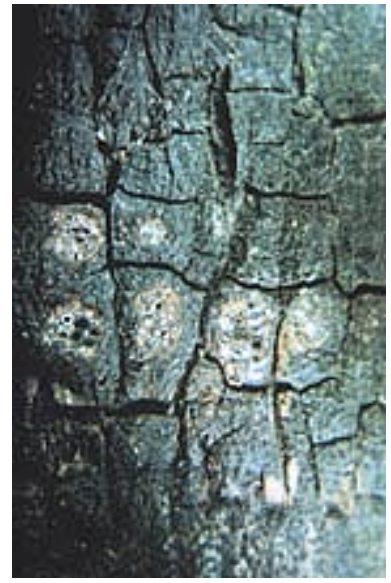

Fig. 6c. Stromatal surface, with exposed perithecial cavities.

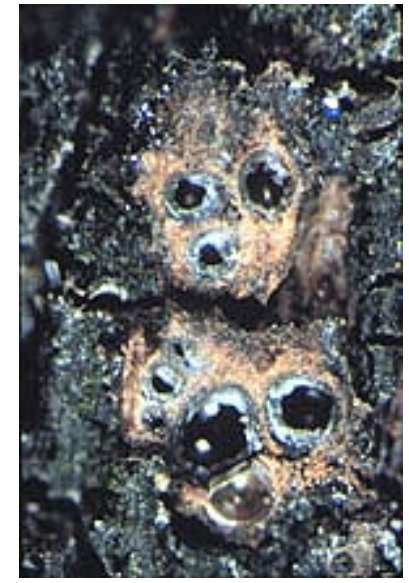

Fig. 6d. Perithecial cavities, demonstrating a shiny inner surface characteristic of mature, dry perithecia.

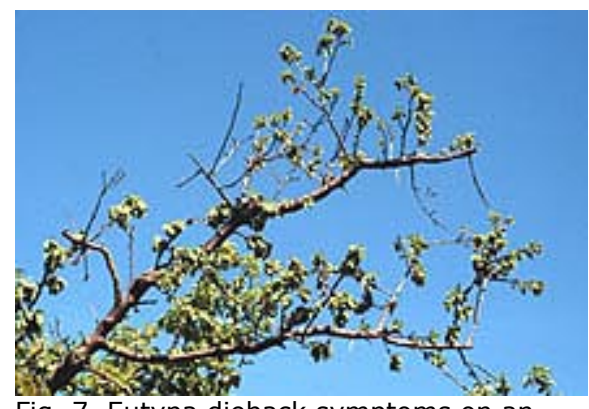

Fig. 7. Eutypa dieback symptoms on an apricot tree.
Apricot. Dieback of apricot also appears more frequently in mature orchards. The first symptom is usually the rapid collapse of a branch during mid-summer (Fig. 7). Leaves suddenly wilt and die, remaining attached to the branch. Examination of the base of the dead branch will reveal a canker surrounding a pruning wound. Most cankers produce large amounts of gum (Fig. 8) (4). The distorted foliage that occurs on grapevines does not occur on apricot, although there may be some stunting and cupping of the leaves prior to collapse of the affected branch. As with grapevines, the fungus spreads toward the trunk, eventually killing the tree. The formation of perithecia is much more common on apricot than grapevine. Symptoms on other Prunus species are similar to those on apricot (Fig. 9).

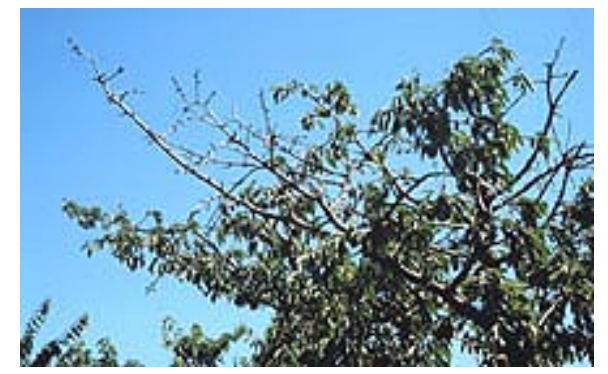




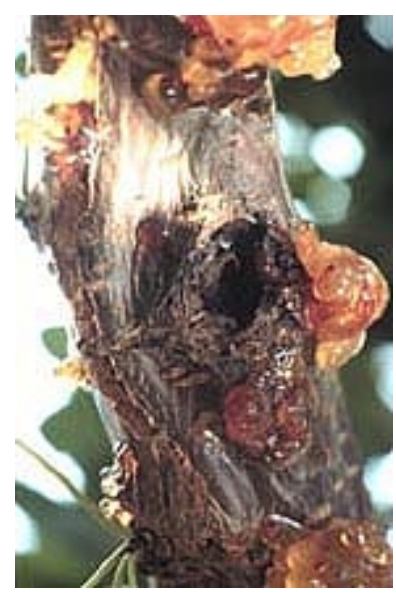

Fig. 8. Excessive gumming at an inoculation site on a cherry branch. This is a symptom characteristic of Eutypa dieback on any Prunus species.
Fig. 9. Eutypa dieback symptoms on a cherry tree.

\section{Host Range}

$E$. lata occurs on at least 88 species of woody dicots in 52 genera (3,5), including many forest and ornamental species. However, it is not certain whether all isolates from native hosts are pathogenic. Pathogenicity of $E$. latahas been confirmed for grapevine, apricot, sweet cherry (Prunus avium L.), chokecherry (Prunus virginiana L. var. demissa [Nutt.] Torr.), sour cherry (Prunus cerasus L.), almond (Prunus dulcis [Mill.] D. Webb), apple (Malus domestica Borkh.), pear (Pyrus communis L.), walnut (Juglans regia L.), olive (Olea europaea L.)(19), and Ceanothus L. spp (3). Natural infection of peach (Prunus persica L.) has not been reported, but isolates from apricot are pathogenic to peach by inoculation. Isolates vary in their aggressiveness, but they do not appear to be host specific.

\section{Geographical Distribution}

E. lata has been reported from Australia, Brazil (14), Canada, Israel, Libya, Mexico, New Zealand, South Africa, the United States, and several countries in Europe. In the U.S., it is found in California, Oregon, Washington, Michigan, and New York (3).

\section{Isolation}

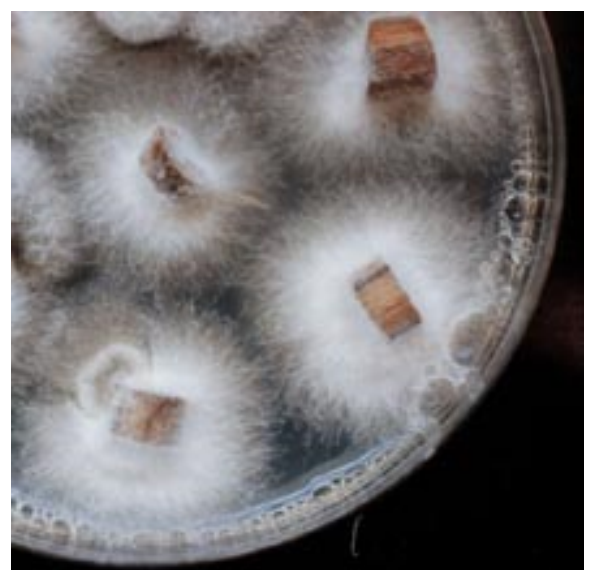

Fig. 10. Cottony white mycelium of Eutypa lata growing from grapevine wood on potato dextrose agar.
E. lata can be isolated only from the perennial wood of the host. The fungus does not progress into the symptomatic grapevine shoots or annual wood. It can be isolated most successfully from the margin of an active canker. Cankers that are very old, so that the dead wood is extremely dry and cracked, are poor specimens for isolation. Branches or cordons should first be stripped of bark. Splitting the wood sections longitudinally exposes internal canker margins, where the fungus can be isolated with the least contamination. Wood chips cut aseptically from the internal canker margin and placed on acidified potato dextrose agar will usually yield the fungus. However, for a higher frequency of pathogen recovery, additional measures can be taken. The following procedure has been used successfully where quantitative data are needed on the frequency of $E$. lata infections. Thin wood chips, up to $1 \mathrm{~cm}^{2}$, are cut from the internal canker margin after splitting the wood. Alternatively, chips can be cut from the exposed external canker margin after removing the bark. Chips are surface disinfested by soaking in $0.5 \% \mathrm{NaOCl}$ for $2 \mathrm{~min}$. Chips are blotted dry and placed on potato dextrose agar amended with $100 \mu \mathrm{g} / \mathrm{ml}$ streptomycin sulfate, $50 \mu \mathrm{g} / \mathrm{ml}$ chlortetracycline $\mathrm{HCl}$, and $5 \mu \mathrm{g} / \mathrm{ml}$ dicloran. The dicloran retards the growth of Rhizopus stolonifer and Botrytis cinerea, which are common contaminants. After 4-7 days at about $24^{\circ} \mathrm{C}$, the fungus grows out as a cottony white mycelium (Fig. 10), and can be transferred to clean culture dishes.

Ascospores can be isolated from fresh perithecia in active stromata $(15,16)$. Old, inactive perithecia are filled with white fungal material, and will not produce ascospores. Fresh perithecia are hollow, shiny, and black inside when dry. Pieces of stromata should be soaked in tap water or distilled water for $1 \mathrm{hr}$ and blotted dry. The pieces are then attached to the lid of a petri dish with petroleum jelly so that the ostioles 
of the perithecia face down. The dishes should be sealed with laboratory film to retain humidity. Ascospores will begin to discharge after a few hours, and will cease to discharge within $24 \mathrm{hr}$. The spores can be discharged onto dry petri dishes, but water agar is preferred. Spore droplets appear golden brown. The spores can be collected from the agar surface by rinsing with sterile water or transferring spore masses to culture media.

\section{Identification}

E. lata can be identified by characteristics of the stromata, asci, and ascospores. Stromata are black, embedded in decorticated wood, are composed of a mixture of fungal and host tissue, and have poorly defined margins. Perithecia, about $0.5 \mathrm{~mm}$ in diameter, are distributed irregularly in one layer. Ostioles are separately erumpent and indistinctly sulcate. Asci (Fig. 11) are 30-60 x 5-7.5 $\mu \mathrm{m}$, with long stipes (60$130 \mu \mathrm{m}$ ), very numerous, spindle-shaped, and eight-spored, with apical invaginations. Ascospores are allantoid, subhyaline, and 7-11 x $2 \mu \mathrm{m}$ (Fig. 12). In mass, they appear golden brown (10). The teleomorph does not develop in culture. Colonies on agar media are at first white and cottony, cream-colored in reverse, with no fruiting structures (Fig. 10). After about $2 \mathrm{wk}$, some cultures develop a gray pigment, and the reverse side may become almost black. After 3-4 wk under continuous fluorescent light, small black pycnidia of the Libertella anamorph are formed. The conidia are exuded in a cream-colored to orange droplet or cirrus. Conidia are filiform, straight or curved, and very numerous, 20-45 x 0.8-1.5 $\mu \mathrm{m}(9)$. They do not germinate readily in culture. Some isolates produce conidia directly on the hyphae (11).

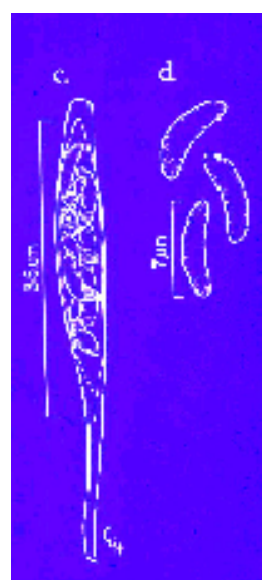

Fig. 11. Ascus of Eutypa lata (=

E. armeniacae).

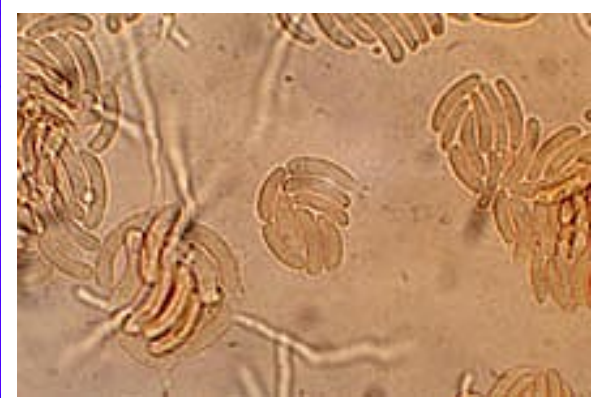

Fig. 12. Ascospores of $E$. lata in octads as discharged from the asci.

\section{Storage}

E. lata is usually stored as mycelium. A simple and effective method of storage has been described by M. V. Carter (7). Plugs are removed from the edge of an active culture and placed in test tubes or vials of sterile water. The tubes are sealed and stored at $2-4^{\circ} \mathrm{C}$. This method reportedly preserves cultures for several years. Ascospores can be stored in the same fashion up to 4 wk. Carter also stored ascospores dry on microscope slides at $2-4^{\circ} \mathrm{C}$ for several months. 


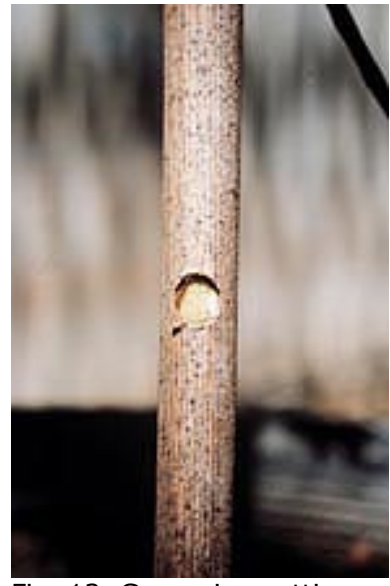

Fig. 13. Grapevine cutting prepared for inoculation.

Pathogenicity tests for $E$. lata require long periods of time. External cankers and shoot symptoms do not develop in grapevine until $2 \mathrm{yr}$ or more after infection. Symptom development occurs more rapidly (about $18 \mathrm{mo}$ ) in apricot. For either host, the procedure is the same. The trunks of young trees or 1-2 yrold grapevine cuttings can be inoculated in the greenhouse or in the field. For older plants, branches (2-4 cm diameter) can be inoculated in the field. If larger branches are used, symptom development will be delayed. When comparing isolates, it is important to use plants of the same cultivar and branches or cuttings of similar age and size. The standard procedure is to remove $1 \mathrm{~cm}$ diameter (or larger) plugs from the bark of the plant using a cork borer. The exposed wood is then scored with a knife to damage the xylem vessels (Fig. 13). A plug of agar from the margin of an actively growing culture is placed in the hole, which is then sealed with laboratory film (6). To induce dieback symptoms in stone fruits, the inoculation site should be adjacent to a lateral branch (Fig. 14). The infection should be allowed to develop for at least one growing season. At that time, a canker may be evident on Prunus species (Fig. 15). Dieback symptoms may require an additional growing season. Xylem necrosis can be observed after one growing season by splitting the inoculated stem or branch (Fig. 16). The extent of xylem discoloration should be compared to controls inoculated with sterile agar. The fungus can be reisolated from the margin of the necrotic area. Inoculations can be performed any time of year, but results may vary with the season. E. lata infects during the dormant season under natural conditions. Pruning wounds can be inoculated instead of cork borer wounds $(12,13)$, but this method is less amenable to measurement of canker expansion. Inoculations can be performed using ascospores $(15,16)$, but this technique is not convenient for pathogenicity testing.

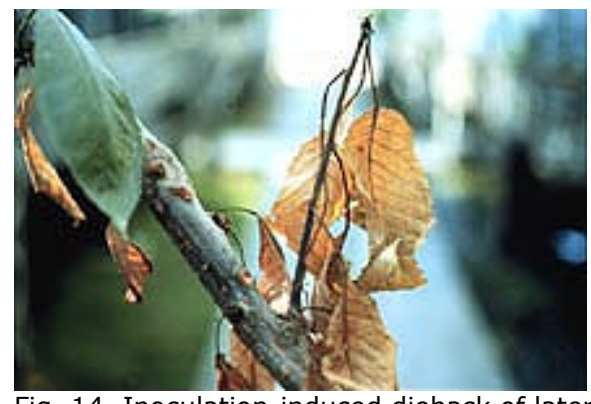

Fig. 14. Inoculation-induced dieback of lateral shoot on a cherry sapling.

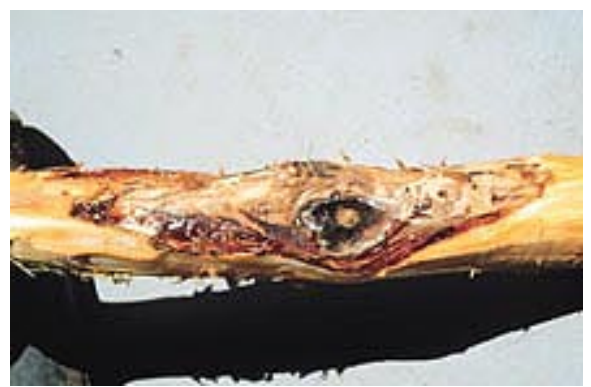

Fig. 15. Xylem canker on a cherry branch 13 mo after inoculation.

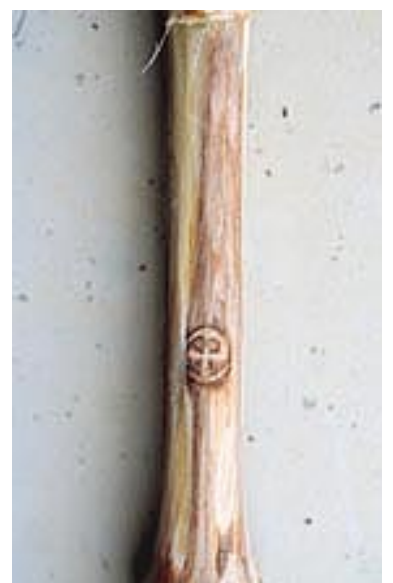

Fig. 16. Xylem discoloration associated with artificial inoculation of a grapevine cutting with $E$. lata.

\section{Literature Cited}

1. Carter, M. V. 1957. Eutypa armeniacae Hansf. \& Carter, sp. nov., an airborne vascular pathogen of Prunus armeniaca L. in southern Australia. Australian J. Botany 5:21-35.

2. Carter, M. V. 1988. Eutypa dieback. Pages 32-34 in: Compendium of Grape Diseases. R. C. Pearson and A. C. Goheen, eds. APS Press, St. Paul, MN.

3. Carter, M. V. 1991. The status of Eutypa lata as a pathogen. Int. Mycol. Inst., Phytopathological Paper No. 32. 
4. Carter, M. V. 1995. Eutypa dieback. Pages 32-33 in: Compendium of Stone Fruit Diseases. J. M. ogawa, E. I. Zehr, G. W. Bird, D. F. Ritchie, K. Uriu, and J. K. Uyemoto, eds. APS Press, St. Paul, MN.

5. Carter, M. V., Bolay, A., and Rappaz, F. 1983. An annotated host list and bibliography of Eutypa armeniacae. Rev. Plant Pathology 62:251-258.

6. Carter, M. V., Bolay, A., and Rumbos, I. 1985. Variation in the pathogenicity of Eutypa lata (= E. armeniacae). Australian J. Botany 33:361-366.

7. Carter, M. V., and English, H. 1994. Long-term storage of Eutypa lata, the cause of an important dieback disease of apricot and grapevine. Plant Dis. 78:925.

8. DeScenzo, R. A., Engel, S.R., Gomez, G., Jackson, E. L., Munkvold, G. P., Weller, J., and Irelan, N. A. 1999. Genetic analysis of Eutypa strains from California supports the presence of two pathogenic species. Phytopathology 89:884-893.

9. Glawe, D. A., and Rodgers, J. D. 1982. Observations on the anamorphs of six species of Eutypa and Eutypella. Mycotaxon 14:334-346.

10. Glawe, D. A., and Rodgers, J. D. 1984. Diatrypaceae in the Pacific Northwest. Mycotaxon 2:401-460.

11. McKemy, J., Glawe, D., and Munkvold, G. P. 1993. A hyphomycetous synanamorph of Eutypa armeniacae in artificial culture. Mycologia 85:941-944.

12. Moller, W. J., and Kasimatis, A. N. 1978. Dieback of grapevines caused by Eutypa armeniacae. Plant Dis. Reptr. 62:254-258.

13. Moller, W. J., and Kasimatis, A. N. 1981. Further evidence that Eutypa armeniacae- not Phomopsis viticola incites dead arm symptoms on grape. Plant Dis. 65:429-431.

14. Paradela Filho, O., Ribeiro, I. J. A., Braga, F. G., Nogueira, E. M. C., Pesce, G., Kuniyuki, H., Fossa, E., Rodrigues, N. J., and Feichtenberger, E. 1993. Eutypa lata, the agent of grape decline in Sao Paolo state. Summa Phytopathologica 19:86-89.

15. Petzoldt, C. H., Moller, W. J., and Sall, M. A. 1981. Eutypa dieback of grapevine: seasonal differences in infection and duration of susceptibility of pruning wounds. Phytopathology 71:540-543.

16. Ramos, D. E., Moller, W. J., and English, H. 1975. Susceptibility of apricot tree pruning wounds to infection by Eutypa armeniacae. Phytopathology 65:1359-1364.

17. Rappaz, F. 1985. The sanctioned species of the genus Eutypa (Diatrypaceae: Ascomycetes): taxonomic and nonmenclatural study. Mycotaxon 20:567-586.

18. Rappaz, F. 1987. Taxonomie et nomenclature des diatrypacees à asques octospores. Mycologia helvetica 2:285648.

19. Rumbos, I. C. 1993. Dieback symptoms on olive trees caused by the fungus Eutypa lata. Bulletin OEPP 23:441445 . 